\title{
Reunión en Cerdeña sobre la cultura de Ozieri
}

Del 15 al 20 de octubre de 1990, se celebró en Cerdeña el Convegno Internazionale sobre "La cultura di Ozieri e il Tempio Rosso di Monte d'Accoddi", centrándose una primera parte de las sesiones sobre el tema concreto de la cultura de Ozieri, y la segunda al monumento de Monte d'Accoddi.

La primera parte se celebró en el Museo Municipal de la pequeña población de Ozieri, en cuyas proximidades está la cueva de San Michele, en la que se descubrieron las primeras muestras de la típica cerámica de esta fase del Neolítico final sardo. Anteriormente se habían celebrado reuniones con la finalidad de poner al día el estado de la investigación, y fruto de ello fue la edición de unas primeras Actas (La cultura di Ozieri. Problematiche e nuove adquisizione, Atti del I Convegno di Studio Ozieri (1986-87), Ozieri, Edic. II Torchietto, 1989), que servian de excelente punto de partida para esta segunda reunión, enfocada ya con caracter internacional.

El encuadre general sobre la cultura de Ozieri estuvo a cargo del prof. Enrico Atzeni, Profesor Ordinario de Antigüedades sardas de la Universidad de Cagliari y Director de la Escuela de especialización de Estudios Sardos, de la misma Universidad. Ello sirvió para precisar los elementos definidores de la cultura, poniendo de manifiesto su riqueza y dinamismo: poblamiento, mundo funerario, manifestaciones artísticas y religiosas, desarrollo económico y tecnológico, con el comienzo de la metalurgia del cobre y la plata y la intensificación del comercio de la obsidiana, con todas sus consecuencias de interrelación con áreas más o menos próximas. Esta primera intervención sirvió además para iniciar el debate en torno a la problemática cultural y cronológica.

La profesora M. Luisa Ferrarese Ceruti, de la Universidad de Cagliari, centró el tema de la "Problemática de las relaciones entre la cultura de Ozieri y el Mediterráneo oriental y central", que sirvió de base a las intervenciones siguientes. La profesora Lucia Vagnetti trató el tema de las relaciones con el mundo Egeo y el Egeo oriental, incidiendo funda- 
mentalmente en los posibles paralelismos formales entre los idolos sardos y los del Egeo, y los problemas cronológicos que plantean, teniendo en cuenta las dataciones absolutas establecidas para la cultura de Ozieri. El profesor David H. Trump, buen conocedor del Neolítico sardo por sus excavaciones en Bonu Ighinu-Mara, trató el tema de las relaciones con Malta, isla en la que centra su actual actividad arqueológica. Sus conclusiones fueron claras respecto a la imposibilidad de una influencia directa de Malta en Cerdeña en ése período, en base a los datos cronológicos, que indican una mayor antigüedad de los elementos sardos sobre los que se habian establecidos paralelismos. El prof. Santo Tinè, de la Universidad de Genova, trató el tema de las relaciones con Sicilia y las islas Eolias, dando lugar a una amplia discusión en torno al difusionismo. El profesor Bernabò Brea, que debía de tratar cuestiones generales de cronología, no pudo asistir.

Ercole Contu, profesor de la Universidad de Sássari, hizo la introducción a la problemática de "Las relaciones entre la cultura de Ozieri e Italia central y meridional y Córcega". La intervención de la prof. Renata Grifoni se centró en la exposición de elementos de comparación concretos procedentes de yacimientos neoliticos de Italia central y el prof. Giuliano Cremonesi incidió en algunos aspectos del Neolítico final y primer Eneolítico de Italia Peninsular, en relación con el contexto de Ozieri. El prof. Claude Weiss se refirió a algunos yacimientos representativos del Neolítico final de Córcega, concretamente a los de Monte Lazzu, Monte Ortu y Pinarolu. Las influencias de la cultura de Ozieri en la producción cerámica del yacimiento de Calanchi y otros del sur de Córcega, fueron tratadas por el prof. Joseph Cesari y, finalmente, el prof. François De Lafranchi trató de las influencias de la cultura de Ozieri en Córcega meridional.

Dentro de la problemática de "Las relaciones entre la cultura de Ozieri e Italia septentrional, Francia y España», intervino en primer lugar el prof. Bernardino Bagolini de la Universidad de Trento, tratando el tema de las relaciones con el Neolítico del norte de Italia. El prof. Jean Guilaine puso de manifiesto elementos de relación con Francia y más concretamente la comprobación del comercio de obsidiana sarda en el sur de Francia, a partir de análisis realizados sobre una serie de piezas procedentes de yacimientos franceses. La que suscribe, expuso una ponencia sobre «El Neolítico final-Calcolítico en España y la cultura de Ozieri».

Las sesiones se completaron con una exposición de posters relativos a excavaciones recientes de la cultura de Ozieri en todo el ámbito de la isla, muy particularmente en el sur, que fueron comentados por el prof. Vincenzo Santoni, Soprintendente de las provincias de Cagliari y Orista- 
no. Una magnífica exposición de diapositivas de gran formato en torno al tema "Arqueología e territorio", acompañada de un espléndido catálogo (Archéologia e territorio, Regione Autonoma della Sardegna, Assessorato della Publica Istruzione, Beni Culturali, Informazione, Spettacolo e Sport. Nuoro, Ed. Ilisso, 1990), fue presentada por la prof. Fulvia Lo Schiavo, Soprintendente de las provincias de Sássari y Nuoro. Se trataba de fotografias aéreas, que daban una magnífica visión de los monumentos arqueológicos y su entorno geográfico, abarcando un amplio espectro cronológico, desde el Neolítico antiguo (Grotta Verde) hasta el martyrium de Santa Filitica di Sorso del siglo v-vı d. C., y el espacio geográfico de las regiones de Sássari y Nuoro. La visita al Museo Arqueoiógico Municipal de Ozieri, con interesantes colecciones locales, fue acompañada por la prof. Paola Basoli.

Una visita a la interesante necrópolis de hipogeos (domus de janas) de Sant Andrea Priu en Bonorva (Sássari), excavados por Taramelli en los años veinte, al poblado y nuraga de Sant Invenia (Porto Torres, Sássari), en curso de excavación, y al Museo Municipal de Ittiredu (Sássari), con interesantes colecciones etnográficas, completaron esta primera parte del Coloquio.

La segunda parte del Coloquio se inició con la visita al Monumento de Monte d'Accoddi en Porto Torres, a unos $11 \mathrm{~km}$. al noroeste de Sássari. Las excavaciones de tan singular yacimiento habian sido iniciadas por el prof. Ercole Contu en los años entre 1952 y 1959 y fueron reanudadas en 1979 por dicho investigador y el prof. Santo Tinè, de la Universidad de Génova, que las ha dirigido entre 1980 y 1989 (TINE, S. y Traverso, A.: Relazione preliminare al Colloquio sul Santuario di Monte d'Accoddi: 10 anni di nuovi scavi, Soprintendenza Archéologica di Sássari e Nuoro, Istituto di Scienze Archéologique, Universita di Genova, Sássari, 1990).

El motivo de esta parte del Coloquio, era precisamente conocer los resultados de los diez últimos años de excavaciones, así como la discusión y debate en torno al tema. Sobre el terreno, en el propio yacimiento, se asistió a la explicación pormenorizada por el prof. Tiné de todos los detalles técnicos de la excavación, asi como de los trabajos de consolidación efectuados posteriormente en la zona ya excavada, a fin de garantizar la conservación del monumento. Una pequeña exposición de materiales en un edificio anexo permitió completar la visión arqueológica del conjunto. Un gran panel explicativo resumia los períodos documentados.

El primer momento de ocupación, estaría representado por un poblado neolítico de cabañas construidas sobre la roca de base, anterior al periodo Ozieri y a la construcción del monumento. A la fase Ozieri co- 
rresponderían los restos de otro poblado de casas rectangulares y el uso del espacio como lugar sacro con la presencia de un menhir al oeste de la rampa de acceso al santuario posterior, y una enorme mesa de piedra interpretada como altar de sacrificios, por los agujeros de sujección que presenta en sus bordes, que servirian para atar a las víctimas. Otros dos menhires se conservan todavía en pie en los alrededores del monumento, a unos $500 \mathrm{~m}$ al este. Todo ello parece revelar un conjunto de caracter religioso de tipo megalítico, dentro del área de un gran poblado todavía poco excavado.

Los datos de excavación indican que el santuario megalítico fue abandonado después de la caida del gran menhir de 4,70 m. de altura. Una datación de $\mathrm{C} 14$ sobre una muestra tomada debajo del menhir caido, dio $2440+-85$ años a.C., que correspondería a un momento final de la cultura de Ozieri, y anterior a su caida. Se ha podido establecer estratigráficamente la caída del menhir, que representaria el final del culto megalítico, con la construcción - superpuesta al basamento del menhirde la rampa de acceso de la primera fase del Monumento Santuario de Monte d'Accoddi.

En el antiguo lugar de culto, se construyó un monumento a todas luces excepcional. Está constituido por una plataforma rectangular de 27,50 por $24 \mathrm{~m}$ en la base, y $5,40 \mathrm{~m}$ de altura, a la que se accedia por una rampa de unos $25 \mathrm{~m}$ de longitud. En el centro de la plataforma, las excavaciones han puesto de manifiesto los restos de una cella rectangular de $12,50 \mathrm{~m}$ por $7,25 \mathrm{~m}$, que, tras los trabajos de restauración, ha quedado diáfana por debajo de la plataforma de la segunda fase. En los muros y pavimento de la cella se conservaban restos de enlucido rojo, lo mismo que en la rampa y algunos puntos de la plataforma. Ello ha hecho que se denomine por sus excavadores a éste primer santuario "El Templo Rojo". Su destrucción por un incendio, comprobado en la cella, obligó a una reconstrucción que llevó consigo a una importante remodelación del conjunto, al parecer en un momento inmediato.

La reedificación del santuario supuso en primer lugar la construcción de un muro perimetral al basamento, que quedó así ampliado hasta alcanzar unas dimensiones de 40 por $30 \mathrm{~m}$, englobando la plataforma anterior y elevándola hasta $9 \mathrm{~m}$. En la parte alta se construyó un nuevo lugar de culto, al que se accedia por una nueva rampa, de mayor anchura y $42 \mathrm{~m}$ de longitud, que terminaba en un escalón, quedando así en el monumento formado por dos terrazas escalonadas.

El abandono del Santuario produjo el deterioro del monumento y su desmoronamiento, hasta convertirse en una pequeña colina artificial, que, 
durante la segunda guerra mundial, fue utilizada como punto de observación para la artilleria de costa, excavándose trincheras que contribuyeron a alterar aún más su estructura.

De los datos de excavación, parece poder deducirse, que el monumental santuario fue construido después de la fase Ozieri, Neolítico final, en el período asimilable a la fase Filigosa, en base a los hallazgos cerámicos, teniendo su continuidad dentro de la fase Abealzu. Su abandono se produciría en la fase Bonnanaro, a comienzos de II milenio. La vigencia del Santuario corresponderia por tanto a la segurida mitad del III milenio, en el periodo Calcolítico sardo, que presenta muchas facetas locales.

Una vez visto y analizado el monumento, se iniciaron las discusiones en torno a él, en un Coloquio celebrado en el Museo Nacional de Arqueologia de Sássari, presidido por el prof. Giorgio Gullini, que abordó el tema de los caracteres arquitectónicos del monumento y más concretamente su estructura escalonada con rampa, extendiéndose ampliamente sobre la estructura del zigurat en el Próximo Oriente. Los profesores Tiné y Contu trataron ampliamente los detalles de la excavación, estructuras constructivas, estratigrafía, encuadre cronológico cultural, aclarando las cuestiones planteadas entre los asistentes tras la visita al monumento. La prof. Ferrarese Ceruti trató de la necrópolis de domus de janas situada en el entorno de Monte d'Accoddi, y la posibilidad de una continuidad de culto entre la fase Ozieri y la posterior representada por el Santuario de Monte d'Accoddi. Tras las numerosas intervenciones de los asistentes, podriamos resumir dos actitudes: las tesis orientalistas y las autoctonistas, más o menos matizadas según los casos, pero que fueron la esencia del debate ante un monumento de tipo religioso realmente singular en el Calcolitico de occidente.

La edición de las Actas, en prensa actualmente en la Universidad de Génova, a cargo del prof. Santo Tinè, pondrá a disposición de los investigadores una gran cantidad de información del mayor interés.

Ana M. ${ }^{a}$ MUÑOz AmiLIBIA 